\title{
Where Text Translation Fails, Art Speaks
}

Using the words of Hans Christian Andersen, "Where words fail, music speaks," and applying them to our thinking about the concept of embodiment as it relates to translation, we open our minds to a wider conception of the ways in which translation affects contemporary ideas of what the field encompasses.

Most of us who teach, study, or practice translation are through force of habit accustomed to think of the act of translation as primarily a linguistic and cultural transfer between text and text. In the applied translation courses, we usually teach from one language to another-French to English, Chinese to German, Spanish to Farsi-eternally pairing two, sometimes quite obstreperous, frenemies: words for words, sense for sense, across the no man's land we face. How to translate a word like patriot? How to handle an apparently simple idiomatic phrase? How to convey a culturally sensitive argument? As translators we love languages, spoken and written, and we love reading the printed word. Yet sometimes our text translations fail us, and it is at these times that art can step in to speak.

We all recognize that text translation involves other kinds of knowing, other knowledge that exists well beyond linguistic competence. These ways of knowing involve a deep understanding of and appreciation for other forms of cultural expression: art, music, dance, political and social structures and tensions, history, religion, philosophy, mythology, poetry, architecture, and sports_-just to name the most obvious.

We know this, we recognize this, and we teach our students the importance of the knowledge that exists beyond textual language per se. However, what if we were somehow trapped by the linguistic texts we carry inside ourselves, even though we might carry a multiplicity of linguistic resources for our work? What if language itself, in its embodied presence within us, could not, for whatever reason, move beyond its interiority and be expressed so that another person could in a way capture it, "understand" it, without words? What if interior embodied language could be translated into a nontextual medium? What if these inarticulacies could allow a different mode of "translation" than the one intended for literate readers who already own the proper linguistic tools key to enter into a written text? What if our embodied interior language could somehow, even awkwardly, move meaning into another "language" that would allow our trapped lexicon with its frozen concepts or trapped inarticulateness, to safely cross our textual no man's land? One basic question remains: what can interior embodied language do when textual production per se is unavailable to it? Or in other words, when faced with the impossibility of producing a linguistic text, how can embodied language successfully emerge? 
Obviously, all of us possess some form of interior embodied language, yet some of us are not able to express it via another text. Thus, for some people, the very idea of "translation" is itself morphed into something new, something different. A translation from embodied language into a visual artifact or into one of the other so-called "fine arts" media simply marks the necessity of saying, stating, and interpreting that which we have no other voice to express. Music, dance, painting, sculpture, and handcrafts - all offer us a way to translate embodied language, to provide a translation of interiorized language that has perhaps been silenced by social or cultural convention.

To examine several real-life examples that answer the above questions, we can look at the Summer 2018 number of Canadian Art, which features a new logo, described by David Balzer, its editor-in-chief, as "fittingly accompanying this issue on translation" (14). Balzer continues by explaining that an expanded view of what translation is and has always been is an important source for illustrating how the embodiment of a creator can be expressed through translation in a medium other than text, through a translation that does not need words (14).

Fan Wu, in an essay entitled "Thresholds," sums it up in this way:

Translation is any transfer from thing or place to another. Beyond and besides language, translation functions as a metaphor: translation between cultures, between art forms, between the living and the ancestral. For my thought to become speech-for my speech to carry gesture - for my gesture to touch another-I translate across my nervous system, my associative web of symbols, the codes of feelings between lovers. (41)

In short, translation conceived of in this way bears responsibility for the preservation of what is incommunicable in language.

One of the most fascinating articles in the Canadian Art's issue on translation focuses on a concept that has become increasingly relevant in current discussions on the movement or "travelling" of translations as it relates to the concept of exile and migration and as these globalized concepts are themselves closely related to translation. The conversation facilitated by Émilie Monnet with four Canadian visual artists in "Beyond Two Solitudes," a conversation on the politics of colonial languages in Quebec, elaborates on the age-old French-English Canadian duality, but in this context we learn about a translational double solitude that goes beyond the simple linguistic duality of Canada's two official languages. Monnet's introduction as well as the four artists' interview responses are presented in both French and English. Monnet begins with an historical reminder of the traditional use of the term "double solitude" but it includes an updated explanation that "double solitude" today most particularly refers to the situation of Canadian Indigenous artists in Quebec. The ways of thinking, the ways of interpreting the physical world around them, and the access for exhibiting their art are all somehow intimately related to whether (or if) the specific artist speaks French or English as the "mother tongue." We learn that ways of thinking and ways of interpreting embedded within language 
are the fundamental keys to individual artistic creations, even requiring that creations move beyond text translation into another medium. Indeed the essay's title is an ironic comment on the inadequacy of the concept of "two solitudes" in relation to Indigenous languages. Given the ages of the four artists interviewed here, the first three (all are fifty and under) came of age when their Indigenous language, their true "mother tongue" perhaps, was either not part of their education or had been lost to the family or repressed by longtime colonial practice in Canada that simply assumed that Indigenous languages would be replaced by English and/or French through the process of assimilation of Indigenous people. The undercurrent of the artistic production of the artists who speak in this essay shows a kind of internal sensation of lack that has been filled through a return to the teachings and languages of their Indigenous roots. The outlier of the group is Rita Letendre, who, as the eldest at 90, appears to have paid little attention to her Indigenous roots, perhaps indeed because her family experiences at a very young age were so painful. It is disappointing that Emilie Monnet has not probed more deeply into the issues embedded in the very term "mother tongue" during her interviews since clearly they add an additional layer of complexity when a lost or forgotten or repressed mother tongue reappears in visual art.

Émilie Monnet herself is an interdisciplinary artist who works in performance and media arts. Her theoretical interests focus on memory, identity, history, and the concept of transformation. The four artists who participate in the Monnet piece come from diverse Nations and generations and have been asked to discuss the impact and influence of language itself on their work and artistic production.

Sonia Robertson was born in Mashteuiash and grew up near Lake Piekuakami (Lac SaintJean) and in 2018 (at age 50) has long kept in close contact with many aspects of Innu culture. Since the 1990s she has participated in many group and solo exhibitions in both Canada and internationally. For Robertson the relation to the spiritual world is the grounding for her creative work.

Art has no language; it is understood beyond words, in its sensations. When I create, I always let myself soak up the spirit of the place where I am. It's that spirit that inspires me and which allows me to translate what the river has to say. French is my mother tongue and even if I do not speak Innu I identify with the perception of the worlds articulated in that language: I understand the concepts, my thinking is circular and anchors itself over a great territory. The fact that I do not speak English and that I reside in Mashteuiash, a remote region, certainly creates barriers to the spread of my work. The voices of francophone Indigenous artists are much less represented in the arts. (55)

Robertson goes on to explain that this lack of representation can perhaps be traced to the fact of later colonization of the West and that in the West, she says, "there was a much stronger will to make us no longer exist" (55). But it is nonetheless clear that for Robertson the political issue is not one that is of critical importance to her. She is much more focused on an embodied language that expresses itself in visual art. Indeed the impression we receive from Robertson's words is that of a visual artist 
whose actual internal language (French) has given way to another language, Innu, one that does not even exist for her textually, but rather serves as the guiding inspiration for the visual art she produces.

In contrast to Sonia Robertson, 38-year-old Euroma Awashish, who has a degree in interdisciplinary art from the University of Quebec Chicoutimi, claims three languages: Atikamekw, French, and English. However, for Awashish the only language that is useful for her in terms of translation is Atikamekw, the interior language that is very seldom "translated" in a traditionally textual way. Awashish explains:

In Atikamekw, there is no word that means artist. We instead refer to the concept that creating is a gift that permits us to honour life by creating beautiful things. Atikamekw is a very visual, metaphorical language, which contains a vision of the world that is unique. My art would be very different if I did not speak my language. I know that this is my wealth, that there is meaning anchored within me. (56)

A bit more optimistic than Robertson, Awashish notes that even though more residency and exchange possibilities exist for anglophone visual artists, there seems to be "a change in the air" and that the francophone Indigenous community now desires to "take more space for ourselves" (56). The thoughtful juxtaposition of "language" and the value of a visual medium in which to "translate" that language underscores Awashish's creative impulse.

The third visual artist included in Monnet's interviews is the very well-known Quebec artist, Rita Letendre. Born in 1928, Letendre, at the age of 90, is the oldest of the interview quartet and has received many honours for her work. She is an Officer of the Order of Canada and a recipient of the 2010 Governor General's Award for Visual and Media Arts. Painter, muralist, and printmaker, Letendre (born in Drummondville) has a fascinating life story and it is clear from her work that travel and lived experiences in several different geographic locales have had deep and lasting influences on her art.

The eldest of seven children, Letendre's family lived in poverty. She suffered a serious injury to one of her fingers when she was very young and at age three was sent to live with her grandmother in Saint-François-du-Lac, where she remained until it was time for her to go to school. When she was seven, her family moved to Saint-Majorique de Grantham. However, since the Letendre children were of Abenaki heritage on their father's side, they experienced incessant and often violent prejudice as did many First Nations children at the time (1930s). It was during her school years that Letendre learned not only to defend herself but also to prefer solitude.

Given the hardships of her early life, Letendre's thoughts in the Monnet essay referring to language and its visual expression are remarkably free of cynicism or resentment about her past. Noting that she had begun her career in Montreal and had lived there for many years, she claims that even today she feels herself a Montrealer. She is also the artist included in Monnet's piece who is the 
clearest about her relationship to language: "I never felt that being an artist who expressed herself in French first was limiting (56). She recalls her meeting with Paul-Emile Borduas and her participation in an Automatiste exhibition in Paris, where she met her future husband-with whom she spoke English. Letendre is definitely the most widely traveled artist of this quartet and happily admits that she speaks French, English, Italian, and Hebrew. Whether or not this variety of spoken languages has been at the heart of her creative practice, Letendre claims not to know. As she says:

For me, languages are above all a way of communicating with other people. It's through painting that I express myself and translate my view on life, the universe, with abstract thinking because the abstract has no barriers and allows everything in the universe to be given. Is that translation of thought linked to my Abenaki roots?Maybe. I don't know. (56)

It is interesting to note here the generational and geographical differences that distinguish Letendre from the other visual artists presented in Monnet's essay. An urban familiarity with linguistic facility with several languages as well as a perhaps successful repression of painful childhood memories connected to her Abenaki heritage leaves Letendre in a different position when it comes to translation as it relates to visual art.

The final artist featured in Monnet's interview article is Martin Akwiranoron Loft, a Kanien'kehaka artist from Kahnawake, who is a printmaker. Born in Kahnawake, Mohawk Territory, in 1960, Loft is also a photographer and craftsperson. A founding member of the Native Indian Inuit Photographers' Association (NIIPA), Loft has exhibited widely in both North America and Europe.

However, Martin Loft is primarily known for his work in the community of Kahnawake, where he is Public Programs Supervisor at the Kanien'kehaka Language and Cultural Centre, where he coordinates community outreach activities, cultural and history workshops, conferences, art workshops and visual arts exhibitions.

Martin Loft is keenly interested in Kanien'kehaka (Mohawk) language and is himself an early graduate of the Mohawk Immersion program. He produces a Mohawk language radio talk show that is streamed live and is an enthusiastic supporter of Indigenous language revitalization. For Martin Loft the relationship between Mohawk language and the totality of his creative practice is an intimate one. In his words:

My art is a reflection of who I am as an Indigenous person (Kanien'kehaka). As an artist, I strive to incorporate the iconography, teaching, and themes as a source of inspiration for my artistic production in a modern setting. I believe each image is a spear of creativity revealed in a tangible form [...] An artifact represents my personal truth and journey. Whether I am working in themedium of photography, printmaking, sliver-smithing, or digital arts, I strive to represent this aspect of myself through creativity, cultural reflection, and historical concerns. (57) 
Of the four artists in Monnet's essay, it is Loft who is clearly the most directly engaged in the world of political and social change, an outward-reaching expressive translation of his embodies Mohawk text into a variety of visual media.

In Kahanawake, we have a long tradition of resistance. We were the first ones to create our own schools 40 years ago, and today about 10 percent of the community are fluent speakers in Kanien'kehaka. (57)

Loft insists that even if people in the audience do not understand the words in Kanien'kehaka that he always inserts into his workshop talks, it is important that they listen and hear their own language - with no textual translation required. As he says, "We don't have to explain everything — the metaphors and symbols embedded in our worldview seep through the cracks of our minds and into the art we make" (57).

Like Robertson and to a lesser extent Aswashish, Loft admits that it is sometimes difficult to exhibit Mohawk works, even in other parts of Quebec: "We don't speak French, and language is a key component to explaining our work and connecting with other artists" (57). Indeed, Loft's art, language, and politics are intimately connected:

There was so much hatred coming from the francophone media and community during the Oka Crisis. On a certain level, we were oblivious to the violence because we did not understand French. That protected us in some way. And for every minute dedicated to learning French we are not learning our own language. (57)

So, with four very different artists who use one or more "text languages" in their daily lives, it seems clear from Robertson that an inner artistic "text" comes from a language she is not able to use in daily life. For Awashish, the inner artist "text" is indeed her Indigenous language_-although that language is merely the source of her artistic production. In the case of Letendre, textual languages in terms of translatability (she has three) seem limited to person-to-person communication in real time whereas her art is inspired perhaps by something from her Indigenous heritage, yet this is not a source she readily recognizes. For Martin Loft his Indigenous Mohawk language, Kanien'kehaka, is definitely both an inner and outer force for both the expression of self and of artistic creation.

A second text in the Translation issue of Canadian Art focuses on an example of visual art that has entirely replaced textual language as we conceive of "text" in the sense of four skills-listening and speaking, reading and writing. Nasrin Himada's epigraph to her essay is yet another adaptation of Hans Christian Andersen's "Where words fail, music speaks. "For Himada the formulation is as follows: "When language fails, what can art tells us about the experiences of exile and the desire to return?" (58). The title to this essay is even more intriguing: "Where I be is with the Image." 
Nasrin Himada is a Palestinian writer and curator in Tio'tia ke (Montreal) in Kanien'kehaka territory. She is not herself a visual artist but rather someone who studies the politics of contemporary art practice with a focus on experimental cinema and media arts. Her essay gives us an example of the moment when textual language per se becomes irrelevant if we consider translation in a more inclusive way.

Himada introduces her essay by giving one of the traditional definitions of translation as transferre (to carry over), writing that she was "thinking about what gets carried over through lineage, and how that becomes a site of return for how we translate our experiences. Language gets carried over. To think through translation is to grapple with the forces at play that condition access to language" (58). [talics mine]

She goes on to describe her relationship to English as "fraught specifically because of my immigrant experience as a child" (58).

Learning English was simultaneous proof of erasure and assimilation. In coming to this place, which is currently called Canada, the language I knew was Arabic. I fell into a disciplined process of forgetting. Because of shame and stigma around not speaking English correctly, and in order to assimilate later, I refused to speak Arabic. (58)

For Himada, learning English and experiencing the difficulties associated with its structures and mechanisms made her realize that "learning this language is not just about getting it right but about understanding when it fails, when it limits thinking and when it just has no words for what it is that I might be thinking or feeling or experiencing" (58).

This important focus on the failure of a second "text language" to fully satisfy the emotional or psychological needs of the language learner allow us a glimpse into a world of translation that may indeed force some creators into areas that are "beyond words. "For Himada then, "[T] he feeling of longing, love, hardline commitment, and unquestionable loyalty to my land (even though I've never been) marks my interest in thinking with images as a way out of the limits of languages" (58). [Italics mine]

Thus, for Nasrin Himada translation always involves a relation to images, not to texts.

Where I be, then, is always in Palestine, but through my relation to images. My relationship to my land, my desire and longing for my land, surpasses the constraints of the English language. Instead I look to images to find other ways of articulating this desire. The process of translating this desire into expression is determined by my love for the image and its capacity to bring me closer to my land. (58)

If the task of translation is to bridge the gap for persons who, for whatever reason, have "lost" language in some profound sense but who feel an equally profound desire to understand and 
experience at least some aspects of the lost or forgotten linguistic text, then the visual image is a method for allowing that transfer or connection to be made.

We have now heard from four practicing Indigenous Canadian artists who have linked text language to their practice of visual art and from a non-practicing artist who nonetheless uses images rather than text language to find understanding and/or interpretive meaning. Perhaps in conclusion we can consider a recent exhibition of Canadian Indigenous art in an attempt to understand the importance of translating beyond text to text.

"Our Languages Live Within Us" by Lindsay Nixon in collaboration with Scott Beneinnaabandan, Joi T. Arcand, Jordan Bennett, and Dee Barsay is a text based on a curated special exhibition at the Winnipeg Art Gallery in the spring of 2018 entitled "Insurgence/ Resurgence. "Although the description of the exhibition in Canadian Art is presented bilingually in both Cree and English, it is easy to hear the Cree behind the English translation:

"Insurgence/Resurgence" this is a Winnipeg gathering. Julie Nagam, she calls them together for the gathering. Jaimie Isaac, she called them together for the gathering. Winnipeg Art Gallery (WAG), that is a building that holds decoration. That is a building that holds relationships.

Those artists over there, they are my relatives. I spoke to my friends in Winnipeg. All of us spoke English because we live in Canada. We were lost. We want to go home. We want to begin becoming good at speaking Cree (here meant as "our languages"). Rise up, my honoured friends. (76)

In the words of Lindsay Nixon, the author of this essay, "I wish I could write this whole introduction in Plains Cree, one of my Indigenous languages. I can't. My brain has been rewired by a foreign language that invaded my head, like an earworm in a Katy Perry song. I think in an English way now" (77).

In some ways Nixon's position vis-à-vis language is similar to Himara's position relating to her Arabic (which she refused to speak) as she was assimilated into English. Nixon describes her linguistic alienation in this way: "I don't know how to express the things I want to say or even if they are translatable because Cree ways of knowing are so radically different from English ways. Cree words express subject relationships — actions, verbs, doing — whereas English expresses object relations and relies on nouns, naming and claiming. My English-mindedness influences the way I conceptually move through the world and how I describe my relationships, relations and actions" (77).

So artistic expression in its Indigeneity must somehow overcome the English-mindedness described by Nixon and attempt to reactivate Indigenous ways of knowing. Thus the "Insurgence/Resurgence" exhibition brought Indigenous artists together as a reminder that 
"Indigenous languages, and the art and curatorial projects they inspire, are activated through intimacy and togetherness" (77).

The translation project is here seen in a different light: that Indigenous "art and curatorial projects" will be the source of what we might qualify as a bizarre back translation into the resurgence of the Indigenous languages themselves.

Language is shared over kitchen tables, taught by grandmas, aunties, and cousins who passed on the relations and teachings anchored in our descriptive language to one another over tea, beading, and gossip. Because Indigenous languages are verb-based, the values and intentions they contain are action based, meant to be activated with one's relations and in community, alongside kin. Indigenous languages are alive. (77)

To illustrate this translation movement from embodied language to visual art as text language, we can consider the contribution of one specific Indigenous artist who exhibited at the Winnipeg Art Gallery's “Insurgence/Resurgence. ”Joi T. Arcand's art aptly demonstrates the epigraph of Nixon's essay: "Words affect the way we make, do, and think. For Indigenous artists, various types of communication don't always translate to English, or to written or spoken language” (76).

Joi Arcand is an artist from Muskeg Lake Cree Nation, Saskatchewan, Treaty 6 Territory, who currently lives in Ottawa. A graduate of the University of Saskatchewan with a BFA, she works in a variety of visual media. Arcand's two works included in "Insurgence/Resurgence" are an LED and neon lights piece with illuminated text in Cree and a second installation piece entitled "Don't Speak English," where Arcand marked off the floor of the stairs leading up to the exhibition with Cree syllabics so that these syllabics could "reclaim the ground, the land, for Cree peoples, and simultaneously refuse settler readings of the space" $(77,80)$.

For Arcand, like all the artists of "Insurgence/Resurgence," language is "an embodied practice miyowawaynamowin (good creation) which allows Indigenous artistic expression in ways that don't always translate to English or to written or spoken language for that matter" (77). The curator's note next to Arcand's vinyl installation on the stairs gives the visitor the following explanatory commentary:

Residential schools stole the words from the ancestors' hearts, minds, and tongues, and along with them their spirits. During Arcand's research Darryl Chamakes, her frequent collaborator and translator, told her that "syllabics" in Plains Cree is cabkipêhikana, translating to "marks representing the spirits of sound." To me, Arcand's work is land and spirit medicine (maskibiki), taking up space and commanding presence in material, form and location. Arcand honours the Indigenous grandparents - who had their language taken and cultural continuity severed from future bloodlines-by marking the space for Cree speakers. 
[...] Cree speakers are now the ones chiding the settlers for speaking out of turn, just as settlers used to punish our ancestors in residential school: Don't speak English. Never forget you're on Cree land, invader. (80)

The world of visual art in the largest sense has an intimate connection to the world of translation. When text languages are in conflict, whether for political or cultural or ethnic reasons, there seems to be a translational way out of the impasse of the "untranslatable" through the world of visual art, whether that be painting, sculpture, photography, installation art, or other digital media. This is particularly true in a globalized world increasingly home to exiles from away and exiles in their own lands. 
TranscUlturAl, vol. 11.1 (2019), 114-124

https://journals.library.ualberta.ca/tc/index.php/tc

\section{REFERENCES}

Balzer, David. “This Issue. ”Canadian Art, vol. 35, no. 2, Summer 2018, p. 14.

Himada, Nasrin. "Where I be is with the Image. " Canadian Art, vol. 35, no. 2, Summer 2018, pp. 58-61.

Monnier, Émilie. “Beyond Two Solitudes. "Canadian Art, vol. 35, no. 2, Summer 2018, pp. 54-57.

Nixon, Lindsay, et al. "Our Languages Live Within Us.” Canadian Art (Summer 2018), pp. 76-81.

Online access to the articles discussed in this essay are available on the website of Canadian Art.

https://canadianart. ca/features/our-languages-live-within-us

https://canadianart. ca/features/?s=where $+\mathrm{i}+\mathrm{be}+\mathrm{is}+\mathrm{with}+$ the + image

https://canadianart. ca/features/beyond-two-solitudes

Images by specific works by artists discussed in this essay:

1. Euroma Awashish, Souffle de vie 2017 (Chinese ink and acrylic on paper with gold leaf, $5.7 \times 60.9 \mathrm{~cm}$ ) (page 54)

2. Martin Akwiranoron Loft, Tattoo \#1 (cover design for Stories of Oka by Isabelle StArmand)(page 57)

3. Joi T. Arcand, "Don't Speak English” (installation, 2017) (page 80)

4. Joi T. Arcand, Ninohtênêhiyawân (LED and neon lights installation, 2017) (page 77) 